Proyecciones Journal of Mathematics

Vol. 33, No 4, pp. 349-367, December 2014.

Universidad Católica del Norte

Antofagasta - Chile

\title{
Companions of Hermite-Hadamard Inequality for Convex Functions (II)
}

\author{
S. S. Dragomir \\ Victoria University, Australia \\ and \\ I. Gomm \\ Victoria University, Australia \\ Received: March 2014. Accepted: July 2014
}

\begin{abstract}
Companions of Hermite-Hadamard inequalities for convex functions defined on the positive axis in the case when the integral has either the weight $\frac{1}{t^{2}}$ or $\frac{1}{t}, t>0$ are given. Applications for special means are provided as well.
\end{abstract}

Subjclass : 26D15; 25D10.

Keywords : Convex functions, Hermite-Hadamard inequality, Special means 


\section{Introduction}

The following integral inequality

$$
f\left(\frac{a+b}{2}\right) \leq \frac{1}{b-a} \int_{a}^{b} f(t) d t \leq \frac{f(a)+f(b)}{2}
$$

which holds for any convex function $f:[a, b] \rightarrow \mathbf{R}$, is well known in the literature as the Hermite-Hadamard inequality.

There is an extensive amount of literature devoted to this simple and nice result which has many applications in the Theory of Special Means and in Information Theory for divergence measures, for which we would like to refer the reader to the papers [1] - [61] and the references therein.

Recently we proved the following Hermite-Hadamard type inequality [22]:

Theorem 1. Let $f:[a, b] \subset(0, \infty) \rightarrow \mathbf{R}$ be a convex function on $[a, b]$, then we have the inequalities

$$
\frac{A\left(\frac{f(a)}{a}, \frac{f(b)}{b}\right)}{G^{2}(a, b)} \geq \frac{1}{b-a} \int_{a}^{b} \frac{1}{t^{3}} f(t) d t \geq \frac{f(H(a, b))}{H(a, b) G^{2}(a, b)}
$$

where

$$
H(p, q):=\frac{2}{\frac{1}{p}+\frac{1}{q}}, G(p, q):=\sqrt{p q} \text { and } A(p, q):=\frac{p+q}{2}
$$

are the Harmonic, Geometric and Arithmetic means, respectively.

If the function $f$ is concave, then the inequalities (1.2) reverse.

Let us recall the following means :

The logarithmic mean:

$$
\mathrm{L}=\mathrm{L}(a, b):=\left\{\begin{array}{ll}
a & \text { if } a=b \\
\frac{b-a}{\ln b-\ln a} & \text { if } a \neq b
\end{array} a, b>0 ;\right.
$$

The identric mean:

$$
\mathrm{I}:=\mathrm{I}(a, b)=\left\{\begin{array}{ll}
a & \text { if } a=b \\
\frac{1}{e}\left(\frac{b^{b}}{a^{a}}\right)^{\frac{1}{b-a}} & \text { if } a \neq b
\end{array} \quad a, b>0 ;\right.
$$

The p-logarithmic mean: 
and $a, b>0$.

$$
\mathrm{L}_{p}=L_{p}(a, b):= \begin{cases}{\left[\frac{b^{p+1}-a^{p+1}}{(p+1)(b-a)}\right]^{\frac{1}{p}}} & \text { if } a \neq b ; \\ a & \text { if } a=b\end{cases}
$$

It is well known that $L_{p}$ is monotonic nondecreasing over $p \in R$ with $L_{-1}:=L$ and $L_{0}:=I$.

In particular, we have the inequalities

$$
H \leq G \leq L \leq I \leq A
$$

Utilising Theorem 1, we can state the following proposition [22]:

Proposition 1. For any $0<a<b$ we have

$$
\begin{gathered}
G^{2} \geq L H, \\
0 \leq A L-G^{2} \leq \frac{1}{4}(b-a)^{2} \frac{A L}{G^{2}}
\end{gathered}
$$

and

$$
0 \leq G^{2}-H L \leq \frac{1}{4}(b-a)^{2} \frac{A L}{G^{2}} .
$$

In this paper we establish some companions of Hermite-Hadamard inequalities for convex functions defined on the positive axis in the case when the integral has either the weight $\frac{1}{t^{2}}$ or $\frac{1}{t}, t>0$. Applications for special means are provided as well.

\section{The Results}

We start with the following companion of Hermite-Hadamard inequality:

Theorem 2. Let $f:[a, b] \subset(0, \infty) \rightarrow \mathbf{R}$ be a convex function on $[a, b]$, then we have the inequalities

$$
\begin{gathered}
\frac{1}{b-a}\left[\frac{L(a, b)-a}{L(a, b)} \cdot \frac{f(a)}{a}+\frac{b-L(a, b)}{L(a, b)} \cdot \frac{f(b)}{b}\right] \\
\geq \frac{1}{b-a} \int_{a}^{b} \frac{1}{t^{2}} f(t) d t \geq \frac{f\left(\frac{G^{2}(a, b)}{L(a, b)}\right)}{G^{2}(a, b)} .
\end{gathered}
$$

If the function $f$ is concave, then the inequalities (2.1) reverse. 
Proof. Define $x:=\frac{1}{b}<\frac{1}{a}:=y$ and take $t, s \in(x, y)$.

By the convexity of $f$ on $[a, b]$ we have

$$
f\left(\frac{1}{t}\right)-f\left(\frac{1}{s}\right) \geq f_{+}^{\prime}\left(\frac{1}{s}\right)\left(\frac{1}{t}-\frac{1}{s}\right) .
$$

Integrating over $t$ on $[x, y]$ and dividing by $y-x$ we get

$$
\frac{1}{y-x} \int_{x}^{y} f\left(\frac{1}{t}\right) d t-f\left(\frac{1}{s}\right) \geq f_{+}^{\prime}\left(\frac{1}{s}\right)\left(\frac{1}{y-x} \int_{x}^{y} \frac{d t}{t}-\frac{1}{s}\right)
$$

for any $s \in(x, y)$.

Since

$$
\frac{1}{y-x} \int_{x}^{y} \frac{d t}{t}=\frac{\ln y-\ln x}{y-x}=\frac{1}{L(x, y)}
$$

then from $(2.2)$ we get

$$
\frac{1}{y-x} \int_{x}^{y} f\left(\frac{1}{t}\right) d t-f\left(\frac{1}{s}\right) \geq f_{+}^{\prime}\left(\frac{1}{s}\right)\left(\frac{1}{L(x, y)}-\frac{1}{s}\right)
$$

for any $s \in(x, y)$.

Taking $s=L(x, y)$ in (2.3) we get the following inequality of interest in itself

$$
\frac{1}{y-x} \int_{x}^{y} f\left(\frac{1}{t}\right) d t \geq f\left(\frac{1}{L(x, y)}\right) .
$$

Changing the variable $u=\frac{1}{t}$ we obtain

$$
\begin{aligned}
& \frac{1}{y-x} \int_{x}^{y} f\left(\frac{1}{t}\right) d t=\frac{1}{y-x} \int_{\frac{1}{y}}^{\frac{1}{x}} \frac{1}{u^{2}} f(u) d u \\
= & \frac{1}{\frac{1}{a}-\frac{1}{b}} \int_{a}^{b} \frac{1}{u^{2}} f(u) d u=\frac{G^{2}(a, b)}{b-a} \int_{a}^{b} \frac{1}{u^{2}} f(u) d u
\end{aligned}
$$

and since

$$
\frac{1}{L(x, y)}=\frac{\ln y-\ln x}{y-x}=\frac{\ln \frac{1}{a}-\ln \frac{1}{b}}{\frac{1}{a}-\frac{1}{b}}=\frac{G^{2}(a, b)}{L(a, b)},
$$

then from (2.4) we get the second inequality in (2.1).

We know that for any convex function $g$ on $[m, M]$ we have the inequality 


$$
\begin{gathered}
\frac{M-v}{M-m} f(m)+\frac{v-m}{M-m} f(M) \\
\geq f\left[\frac{(M-v) m+(v-m) M}{M-m}\right]=f(v)
\end{gathered}
$$

for any $v \in[m, M]$.

Now, if we write the inequality (2.5) for $m=\frac{1}{y}=a, v=\frac{1}{t}$ and $M=$ $\frac{1}{x}=b$ then we get

$$
\frac{\frac{1}{x}-\frac{1}{t}}{\frac{1}{x}-\frac{1}{y}} f\left(\frac{1}{y}\right)+\frac{\frac{1}{t}-\frac{1}{y}}{\frac{1}{x}-\frac{1}{y}} f\left(\frac{1}{x}\right) \geq f\left(\frac{1}{t}\right)
$$

for any $t \in[x, y]$, which is equivalent to

$$
\frac{x y}{y-x}\left[\left(\frac{1}{x}-\frac{1}{t}\right) f\left(\frac{1}{y}\right)+\left(\frac{1}{t}-\frac{1}{y}\right) f\left(\frac{1}{x}\right)\right] \geq f\left(\frac{1}{t}\right)
$$

for any $t \in[x, y]$.

Integrating (2.6) over $t$ on $[x, y]$ and dividing by $y-x$ we get

$$
\begin{gathered}
\frac{x y}{y-x}\left[\left(\frac{1}{x}-\frac{1}{L(x, y)}\right) f\left(\frac{1}{y}\right)+\left(\frac{1}{L(x, y)}-\frac{1}{y}\right) f\left(\frac{1}{x}\right)\right] \\
\geq \frac{1}{y-x} \int_{x}^{y} f\left(\frac{1}{t}\right) d t
\end{gathered}
$$

which is an inequality of interest in itself.

Writing the inequality (2.7) in terms of $a$ and $b$ we obtain

$$
\begin{gathered}
\frac{1}{b-a}\left[\left(b-\frac{G^{2}(a, b)}{L(a, b)}\right) f(a)+\left(\frac{G^{2}(a, b)}{L(a, b)}-a\right) f(b)\right] \\
\geq \frac{G^{2}(a, b)}{b-a} \int_{a}^{b} \frac{1}{u^{2}} f(u) d u .
\end{gathered}
$$

Since

$$
\begin{gathered}
\left(b-\frac{G^{2}(a, b)}{L(a, b)}\right) f(a)=b a\left(1-\frac{a}{L(a, b)}\right) \frac{f(a)}{a} \\
=G^{2}(a, b) \cdot \frac{L(a, b)-a}{L(a, b)} \cdot \frac{f(a)}{a}
\end{gathered}
$$

and 


$$
\begin{gathered}
\left(\frac{G^{2}(a, b)}{L(a, b)}-a\right) f(b)=a b\left(\frac{b}{L(a, b)}-1\right) \frac{f(b)}{b} \\
=G^{2}(a, b) \cdot \frac{b-L(a, b)}{L(a, b)} \cdot \frac{f(b)}{b}
\end{gathered}
$$

then by (2.8) we get

$$
\begin{gathered}
\frac{1}{b-a}\left[G^{2}(a, b) \cdot \frac{L(a, b)-a}{L(a, b)} \cdot \frac{f(a)}{a}+G^{2}(a, b) \cdot \frac{b-L(a, b)}{L(a, b)} \cdot \frac{f(b)}{b}\right] \\
\geq \frac{G^{2}(a, b)}{b-a} \int_{a}^{b} \frac{1}{u^{2}} f(u) d u .
\end{gathered}
$$

Finally, dividing by $G^{2}(a, b)$ we get the first inequality in (2.1).

We have the following result as well:

Theorem 3. Let $f:[a, b] \subset(0, \infty) \rightarrow \mathbf{R}$ be a convex function on $[a, b]$, then we have the inequalities

$$
\begin{gathered}
\frac{1}{b-a}\left[\frac{b-L(a, b)}{L(a, b)} f(a)+\frac{L(a, b)-a}{L(a, b)} f(b)\right] \\
\geq \frac{1}{b-a} \int_{a}^{b} \frac{1}{t} f(t) d t \geq \frac{f(L(a, b))}{L(a, b)} .
\end{gathered}
$$

If the function $f$ is concave, then the inequalities (2.9) reverse.

Proof. By the convexity of $f$ we have

$$
f(t)-f(s) \geq f_{+}^{\prime}(s)(t-s)
$$

for any $t, s \in(a, b)$.

If we multiply this inequality by $\frac{1}{t}$ and integrate over $t$ on $[a, b]$ we get by division with $b-a$

$$
\frac{1}{b-a} \int_{a}^{b} \frac{f(t)}{t} d t-f(s) \frac{1}{b-a} \int_{a}^{b} \frac{1}{t} d t \geq f_{+}^{\prime}(s)\left(1-s \frac{1}{b-a} \int_{a}^{b} \frac{1}{t} d t\right)
$$


and since

$$
\frac{1}{b-a} \int_{a}^{b} \frac{1}{t} d t=\frac{1}{L(a, b)}
$$

then we get from (2.10) the inequality

$$
\frac{1}{b-a} \int_{a}^{b} \frac{f(t)}{t} d t-\frac{f(s)}{L(a, b)} \geq f_{+}^{\prime}(s)\left(1-\frac{s}{L(a, b)}\right)
$$

for any $s \in(a, b)$, which is an inequality of interest in itself.

By taking $s=L(a, b)$ in (2.11) we get the second inequality in (2.5).

From the inequality (2.5) we get

$$
\frac{b-t}{b-a} f(a)+\frac{t-a}{b-a} f(b) \geq f(t)
$$

for any $t \in[a, b]$.

If we multiply this inequality by $\frac{1}{t}$ and integrate over $t$ on $[a, b]$ we get by division with $b-a$

$$
\frac{b \frac{1}{b-a} \int_{a}^{b} \frac{1}{t} d t-1}{b-a} f(a)+\frac{1-a \frac{1}{b-a} \int_{a}^{b} \frac{1}{t} d t}{b-a} f(b) \geq \frac{1}{b-a} \int_{a}^{b} \frac{f(t)}{t} d t
$$

which is equivalent to

$$
\frac{\frac{b}{L(a, b)}-1}{b-a} f(a)+\frac{1-\frac{a}{L(a, b)}}{b-a} f(b) \geq \frac{1}{b-a} \int_{a}^{b} \frac{f(t)}{t} d t,
$$

which proves the first inequality as well.

\section{Applications for Special Means}

We have:

Proposition 2. For any $0<a<b$ we have

$$
b^{\frac{b-L(a, b)}{b-a}} a^{\frac{L(a, b)-a}{b-a}} \geq G(a, b) .
$$

Proof. Using the inequality (2.1) for the convex function $f:[a, b] \subset$ $(0, \infty) \rightarrow \mathbf{R}, f(t)=t \ln t$ we get 


$$
\begin{aligned}
& \frac{1}{b-a}\left[\frac{L(a, b)-a}{L(a, b)} \cdot \ln a+\frac{b-L(a, b)}{L(a, b)} \cdot \ln b\right] \\
& \geq \frac{1}{b-a} \int_{a}^{b} \frac{1}{t} \ln (t) d t \geq \frac{\frac{G^{2}(a, b)}{L(a, b)} \ln \left(\frac{G^{2}(a, b)}{L(a, b)}\right)}{G^{2}(a, b)} .
\end{aligned}
$$

Observe that

$$
\begin{aligned}
& \frac{1}{b-a} \int_{a}^{b} \frac{1}{t} \ln (t) d t=\frac{1}{2} \frac{(\ln b)^{2}-(\ln a)^{2}}{b-a} \\
& =\frac{1}{2} \frac{[\ln b-\ln a][\ln b+\ln a]}{b-a}=\frac{\ln G(a, b)}{L(a, b)}
\end{aligned}
$$

and

$$
\begin{gathered}
\frac{1}{b-a}\left[\frac{L(a, b)-a}{L(a, b)} \cdot \ln a+\frac{b-L(a, b)}{L(a, b)} \cdot \ln b\right] \\
=\ln \left[b^{\frac{b-L(a, b)}{(b-a) L(a, b)}} a^{\frac{L(a, b)-a}{(b-a) L(a, b)}}\right]
\end{gathered}
$$

then by (3.2) we get

$$
\ln \left[b^{\frac{b-L(a, b)}{(b-a) L(a, b)}} a^{\frac{L(a, b)-a}{(b-a) L(a, b)}}\right] \geq \ln [G(a, b)]^{\frac{1}{L(a, b)}} \geq \ln \left(\frac{G^{2}(a, b)}{L(a, b)}\right)^{\frac{1}{L(a, b)}}
$$

which is equivalent to

$$
b^{\frac{b-L(a, b)}{(b-a) L(a, b)}} a^{\frac{L(a, b)-a}{(b-a) L(a, b)}} \geq[G(a, b)]^{\frac{1}{L(a, b)}} \geq\left(\frac{G^{2}(a, b)}{L(a, b)}\right)^{\frac{1}{L(a, b)}} .
$$

Taking the power $L(a, b)$ in (3.5) we obtain

$$
b^{\frac{b-L(a, b)}{b-a}} a^{\frac{L(a, b)-a}{b-a}} \geq G(a, b) \geq \frac{G^{2}(a, b)}{L(a, b)} .
$$

The second inequality in (3.6) is obvious, so we drop it. The following result also holds:

Proposition 3. For any $0<a<b$ we have 


$$
\begin{gathered}
\frac{G^{2}(a, b)}{b-a}\left[\frac{L(a, b)-a}{L(a, b)} \cdot \frac{\ln \left(\frac{1}{a}\right)}{a}+\frac{b-L(a, b)}{L(a, b)} \cdot \frac{\ln \left(\frac{1}{b}\right)}{b}\right] \\
\geq \ln I\left(\frac{1}{b}, \frac{1}{a}\right)
\end{gathered}
$$

Proof. If we write the inequality (2.1) for the concave function $f$ : $[a, b] \subset(0, \infty) \rightarrow \mathbf{R}, f(t)=\ln t$ we have

$$
\begin{gathered}
\frac{1}{b-a}\left[\frac{L(a, b)-a}{L(a, b)} \cdot \frac{\ln (a)}{a}+\frac{b-L(a, b)}{L(a, b)} \cdot \frac{\ln (b)}{b}\right] \\
\leq \frac{1}{b-a} \int_{a}^{b} \frac{1}{t^{2}} \ln (t) d t \leq \frac{\ln \left(\frac{G^{2}(a, b)}{L(a, b)}\right)}{G^{2}(a, b)} .
\end{gathered}
$$

Integrating by parts, we have

$$
\begin{gathered}
\frac{1}{b-a} \int_{a}^{b} \frac{1}{t^{2}} \ln (t) d t=-\frac{1}{b-a} \int_{a}^{b} \ln (t) d\left(\frac{1}{t}\right) \\
=-\frac{1}{b-a}\left[\left.\frac{1}{t} \ln (t)\right|_{a} ^{b}-\int_{a}^{b} \frac{1}{t^{2}} d t\right] \\
=-\frac{1}{b-a}\left[\frac{1}{b} \ln (b)-\frac{1}{a} \ln (a)+\left.\frac{1}{t}\right|_{a} ^{b}\right] \\
=-\frac{1}{b-a}\left[\frac{1}{b} \ln (b)-\frac{1}{a} \ln (a)+\frac{1}{b}-\frac{1}{a}\right] \\
=-\frac{1}{b-a}\left[\frac{1}{b} \ln (b)-\frac{1}{a} \ln (a)+\frac{1}{b}-\frac{1}{a}\right] \\
=\frac{1}{b-a}\left[\frac{1}{b} \ln \left(\frac{1}{b}\right)-\frac{1}{a} \ln \left(\frac{1}{a}\right)-\frac{1}{b}+\frac{1}{a}\right] \\
=\frac{1}{b-a}\left[\frac{1}{b} \ln \left(\frac{1}{b}\right)-\frac{1}{a} \ln \left(\frac{1}{a}\right)\right]+\frac{1}{b a} .
\end{gathered}
$$

Observe that 


$$
K=-\frac{1}{b a}\left[\frac{1}{\frac{1}{b}-\frac{1}{a}}\left[\frac{1}{b} \ln \left(\frac{1}{b}\right)-\frac{1}{a} \ln \left(\frac{1}{a}\right)\right]-1\right]=-\frac{\ln I\left(\frac{1}{b}, \frac{1}{a}\right)}{G^{2}(a, b)}
$$

then by (3.8) we get

$$
\begin{gathered}
\frac{1}{b-a}\left[\frac{L(a, b)-a}{L(a, b)} \cdot \frac{\ln (a)}{a}+\frac{b-L(a, b)}{L(a, b)} \cdot \frac{\ln (b)}{b}\right] \\
\leq-\frac{\ln I\left(\frac{1}{b}, \frac{1}{a}\right)}{G^{2}(a, b)} \leq \frac{\ln \left(\frac{G^{2}(a, b)}{L(a, b)}\right)}{G^{2}(a, b)} .
\end{gathered}
$$

If we multiply this inequality by $-G^{2}(a, b)<0$ we get

$$
\begin{gathered}
\frac{G^{2}(a, b)}{b-a}\left[\frac{L(a, b)-a}{L(a, b)} \cdot \frac{\ln \left(\frac{1}{a}\right)}{a}+\frac{b-L(a, b)}{L(a, b)} \cdot \frac{\ln \left(\frac{1}{b}\right)}{b}\right] \\
\geq \ln I\left(\frac{1}{b}, \frac{1}{a}\right) \geq \ln \left(\frac{L(a, b)}{G^{2}(a, b)}\right)
\end{gathered}
$$

and the inequality (3.7) is proved.

We notice that the second inequality is obvious, since

$$
\begin{gathered}
I\left(\frac{1}{b}, \frac{1}{a}\right) \geq L\left(\frac{1}{b}, \frac{1}{a}\right)=\frac{\frac{1}{b}-\frac{1}{a}}{\ln \frac{1}{b}-\ln \frac{1}{a}} \\
\quad=\frac{a-b}{\ln a-\ln b} \cdot \frac{1}{a b}=\frac{L(a, b)}{G^{2}(a, b)},
\end{gathered}
$$

so we drop it.

We have:

Proposition 3. For any $0<a<b$ and $p \in(-\infty, 0) \cup(1, \infty) \backslash\{2\}$ we have

$$
\begin{gathered}
\frac{1}{b-a}\left[\frac{L(a, b)-a}{L(a, b)} \cdot a^{p-1}+\frac{b-L(a, b)}{L(a, b)} \cdot b^{p-1}\right] \\
\geq L_{p-1}^{p-1}(a, b) \geq \frac{G^{2 p-2}(a, b)}{L^{p}(a, b)} .
\end{gathered}
$$


Proof. Consider the function $f:[a, b] \rightarrow(0, \infty), f(t)=t^{p}$ with $p \in$ $(-\infty, 0) \cup(1, \infty) \backslash\{2\}$, then $f$ is convex on $[a, b]$ and if we apply the inequality (2.1), we get

$$
\begin{gathered}
\frac{1}{b-a}\left[\frac{L(a, b)-a}{L(a, b)} \cdot a^{p-1}+\frac{b-L(a, b)}{L(a, b)} \cdot b^{p-1}\right] \\
\geq \frac{1}{b-a} \int_{a}^{b} t^{p-2} d t \geq \frac{G^{2 p-2}(a, b)}{L^{p}(a, b)} .
\end{gathered}
$$

Since

$$
\frac{1}{b-a} \int_{a}^{b} t^{p-2} d t=L_{p-1}^{p-1}(a, b)
$$

then by (3.11) we get the desired result (3.9).

Utilising Theorem 3 we can get the following inequalities for means:

Proposition 5. For any $0<a<b$ we have

$$
a^{a \frac{b-L(a, b)}{(b-a) L(a, b)}} b^{b \frac{L(a, b)-a}{(b-a) L(a, b)}} \geq I(a, b) .
$$

Proof. Using the inequality (2.9) for the convex function $f:[a, b] \subset$ $(0, \infty) \rightarrow \mathbf{R}, f(t)=t \ln t$ we get

$$
\begin{gathered}
\frac{1}{b-a}\left[\frac{b-L(a, b)}{L(a, b)} a \ln a+\frac{L(a, b)-a}{L(a, b)} b \ln b\right] \\
\geq \frac{1}{b-a} \int_{a}^{b} \ln t d t \geq \ln (L(a, b))
\end{gathered}
$$

and since

$$
\frac{1}{b-a} \int_{a}^{b} \ln t d t=\ln I(a, b)
$$

and

$$
\begin{gathered}
\frac{b-L(a, b)}{(b-a) L(a, b)} a \ln a+\frac{L(a, b)-a}{(b-a) L(a, b)} b \ln b \\
=\ln \left[a^{\frac{b-L(a, b)}{(b-a) L(a, b)}} a b^{\frac{L(a, b)-a}{(b-a) L(a, b)}} b\right],
\end{gathered}
$$

then by (3.12) we get

$$
\ln \left[a^{\frac{b-L(a, b)}{(b-a) L(a, b)} a} b^{\frac{L(a, b)-a}{(b-a) L(a, b)} b}\right] \geq \ln I(a, b) \geq \ln (L(a, b)) .
$$


The second inequality is obvious and we drop it.

Proposition 6. For any $0<a<b$ we have

$$
G(a, b) \geq a^{\frac{b-L(a, b)}{b-a}} b^{\frac{L(a, b)-a}{b-a}} .
$$

Proof. Using the inequality (2.9) for the concave function $f:[a, b] \subset$ $(0, \infty) \rightarrow \mathbf{R}, f(t)=\ln t$ we get

$$
\begin{gathered}
\frac{1}{b-a}\left[\frac{b-L(a, b)}{L(a, b)} \ln (a)+\frac{L(a, b)-a}{L(a, b)} \ln (b)\right] \\
\leq \frac{1}{b-a} \int_{a}^{b} \frac{1}{t} \ln t d t \leq \frac{\ln (L(a, b))}{L(a, b)} .
\end{gathered}
$$

However

$$
\frac{1}{b-a} \int_{a}^{b} \frac{1}{t} \ln t d t=\frac{\ln G(a, b)}{L(a, b)}
$$

and since

$$
\begin{gathered}
\frac{1}{b-a}\left[\frac{b-L(a, b)}{L(a, b)} \ln (a)+\frac{L(a, b)-a}{L(a, b)} \ln (b)\right] \\
=\ln \left[a^{\frac{b-L(a, b)}{(b-a) L(a, b)}} b^{\frac{L(a, b)-a}{(b-a) L(a, b)}}\right],
\end{gathered}
$$

then by (3.12) we get

$$
\ln \left[a^{\frac{b-L(a, b)}{(b-a) L(a, b)}} b^{\frac{L(a, b)-a}{(b-a) L(a, b)}}\right] \leq \ln G(a, b)^{\frac{1}{L(a, b)}} \leq \ln \left(L(a, b)^{\frac{1}{L(a, b)}}\right)
$$

i.e.

$$
a^{\frac{b-L(a, b)}{(b-a) L(a, b)}} b^{\frac{L(a, b)-a}{(b-a) L(a, b)}} \leq G(a, b)^{\frac{1}{L(a, b)}} \leq L(a, b)^{\frac{1}{L(a, b)}} .
$$

Taking the power $L(a, b)>0$ we get

$$
a^{\frac{b-L(a, b)}{b-a}} b^{\frac{L(a, b)-a}{b-a}} \leq G(a, b) \leq L(a, b) .
$$

The second inequality is obvious and we drop it.

Finally, we have:

Proposition 7. For any $0<a<b$ and $p \in(-\infty, 0) \cup(1, \infty)$ we have 


$$
\begin{gathered}
\frac{1}{b-a}\left[\frac{L(a, b)-a}{L(a, b)} \cdot a^{p-1}+\frac{b-L(a, b)}{L(a, b)} \cdot b^{p-1}\right] \\
\geq L_{p-1}^{p-1}(a, b) \geq L^{p-1}(a, b) .
\end{gathered}
$$

Proof. Consider the function $f:[a, b] \rightarrow(0, \infty), f(t)=t^{p}$ with $p \in$ $(-\infty, 0) \cup(1, \infty)$, then $f$ is convex on $[a, b]$ and if we apply the inequality (2.9), we get

$$
\begin{gathered}
\frac{1}{b-a}\left[\frac{b-L(a, b)}{L(a, b)} a^{p}+\frac{L(a, b)-a}{L(a, b)} b^{p}\right] \\
\geq \frac{1}{b-a} \int_{a}^{b} t^{p-1} d t \geq \frac{(L(a, b))^{p}}{L(a, b)}=(L(a, b))^{p-1} .
\end{gathered}
$$

Since

$$
\frac{1}{b-a} \int_{a}^{b} t^{p-1} d t=L_{p}^{p}(a, b)
$$

then by (3.16) we get the desired result (3.15).

\section{References}

[1] G. ALLASIA, C. GIORDANO, J. PEČARIĆ, Hadamard-type inequalities for $(2 r)$-convex functions with applications, Atti Acad. Sci. Torino-Cl. Sc. Fis., 133, pp. 1-14, (1999).

[2] H. ALZER, A note on Hadamard's inequalities, C.R. Math. Rep. Acad. Sci. Canada, 11, pp. 255-258, (1989).

[3] H. ALZER, On an integral inequality, Math. Rev. Anal. Numer. Theor. Approx., 18, pp. 101-103, (1989).

[4] A. G. AZPEITIA, Convex functions and the Hadamard inequality, Rev.-Colombiana-Mat., 28 (1), pp. 7-12, (1994).

[5] D. BARBU, S. S. DRAGOMIR and C. BUŞE, A probabilistic argument for the convergence of some sequences associated to Hadamard's inequality, Studia Univ. Babeş-Bolyai, Math., 38 (1), pp. 29-33, (1993). 
[6] C. BUŞE, S. S. DRAGOMIR and D. BARBU, The convergence of some sequences connected to Hadamard's inequality, Demostratio Math., 29 (1), pp. 53-59, (1996).

[7] S. S. DRAGOMIR, A mapping in connection to Hadamard's inequalities, An. Öster. Akad. Wiss. Math.-Natur., (Wien), 128, pp. 17-20. MR 934:26032. ZBL No. 747:26015, (1991).

[8] S. S. DRAGOMIR, A refinement of Hadamard's inequality for isotonic linear functionals, Tamkang J. of Math. (Taiwan), 24, pp. 101-106. MR 94a: 26043. 2BL No. 799: 26016, (1993).

[9] S. S. DRAGOMIR, On Hadamard's inequalities for convex functions, Mat. Balkanica, 6, pp. 215-222. MR: 934, (1992). 26033.

[10] S. S. DRAGOMIR, On Hadamard's inequality for the convex mappings defined on a ball in the space and applications, Math. Ineq. 83 Appl., 3 (2), pp. 177-187, (2000).

[11] S. S. DRAGOMIR, On Hadamard's inequality on a disk, Journal of Ineq. in Pure \& Appl. Math., 1, No. 1, Article 2, http://jipam.vu.edu.au/, (2000).

[12] S. S. DRAGOMIR, Some integral inequalities for differentiable convex functions, Contributions, Macedonian Acad. of Sci. and Arts, 13 (1), pp. 13-17, (1992).

[13] S. S. DRAGOMIR, Some remarks on Hadamard's inequalities for convex functions, Extracta Math., 9 (2), pp. 88-94, (1994).

[14] S.S. DRAGOMIR, Two mappings in connection to Hadamard's inequalities, J. Math. Anal. Appl., 167, pp. 49-56. MR:934:26038, ZBL No. 758:26014, (1992).

[15] S. S. DRAGOMIR, An inequality improving the first HermiteHadamard inequality for convex functions defined on linear spaces and applications for semi-inner products, J. Inequal. Pure Appl. Math. 3, No. 2, Article 31, (2002).

[16] S. S. DRAGOMIR, An inequality improving the second HermiteHadamard inequality for convex functions defined on linear spaces and applications for semi-inner products, J. Inequal. Pure Appl. Math. 3, No. 3, Article 35, (2002). 
[17] S.S . DRAGOMIR and R. P. AGARWAL, Two new mappings associated with Hadamard's inequalities for convex functions, Appl. Math. Lett., 11, No. 3, pp. 33-38, (1998).

[18] S. S. DRAGOMIR and C. BUŞE, Refinements of Hadamard's inequality for multiple integrals, Utilitas Math (Canada), 47, pp. 193-195, (1995).

[19] S. S. DRAGOMIR, Y. J. CHO and S. S. KIM, Inequalities of Hadamard's type for Lipschitzian mappings and their applications, J. of Math. Anal. Appl., 245 (2), pp. 489-501, (2000).

[20] S. S. DRAGOMIR and I. GOMM, Bounds for two mappings associated to the Hermite-Hadamard inequality, Aust. J. Math. Anal. Appl., 8, Art. 5, 9 pages, (2011).

[21] S. S. DRAGOMIR and I. GOMM, Some new bounds for two mappings related to the Hermite-Hadamard inequality for convex functions, Num. Alg. Cont. $\&$ Opt. 2, No. 2, pp. 271-278, (2012).

[22] S. S. DRAGOMIR and I. GOMM, Companions of Hermite-Hadamard Inequality for Convex Functions (I), Preprint RGMIA Res. Rep. Coll., 17 (2014), Art.

[23] S. S. DRAGOMIR and S. FITZPATRICK, The Hadamard's inequality for $s$-convex functions in the first sense, Demonstratio Math., 31 (3), pp. 633-642, (1998).

[24] S. S. DRAGOMIR and S. FITZPATRICK, The Hadamard's inequality for $s$-convex functions in the second sense, Demonstratio Math., 32 (4), pp. 687-696, (1999).

[25] S. S. DRAGOMIR and N. M. IONESCU, On some inequalities for convex-dominated functions, Anal. Num. Theor. Approx., 19, pp. 2128. MR 936: 26014 ZBL No. 733 : 26010, (1990).

[26] S. S. DRAGOMIR, D. S. MILOŚEVIĆ and J. SÁNDOR, On some refinements of Hadamard's inequalities and applications, Univ. Belgrad, Publ. Elek. Fak. Sci. Math., 4, pp. 21-24, (1993).

[27] S.S. DRAGOMIR and B. MOND, On Hadamard's inequality for a class of functions of Godunova and Levin, Indian J. Math., 39, No. 1, pp. 1-9, (1997). 
[28] S. S. DRAGOMIR and C. E. M. PEARCE, Quasi-convex functions and Hadamard's inequality, Bull. Austral. Math. Soc., 57 , pp. 377385, (1998).

[29] S.

S. DRAGOMIR and C. E. M. PEARCE, Selected Topics on HermiteHadamard Inequalities and Applications, RGMIA Monographs, (2000). [Online http://rgmia.org/monographs/hermite_hadamard.html].

[30] S. S. DRAGOMIR, C. E. M. PEARCE and J. E. PEČARIĆ, On Jessen's and related inequalities for isotonic sublinear functionals, Acta Math. Sci. (Szeged), 61, pp. 373-382, (1995).

[31] S. S. DRAGOMIR, J. E. PEČARIĆ and L. E. PERSSON, Some inequalities of Hadamard type, Soochow J. of Math. (Taiwan), 21, pp. 335-341, (1995).

[32] S. S. DRAGOMIR, J. E. PEČARIĆ and J. SÁNDOR, A note on the Jensen-Hadamard inequality, Anal. Num. Theor. Approx., 19, pp. 2128. MR 93b : 260 14.ZBL No. 733 : 26010, (1990).

[33] S. S. DRAGOMIR and G. H. TOADER, Some inequalities for $m-$ convex functions, Studia Univ. Babeş-Bolyai, Math., 38 (1), pp. 21-28, (1993).

[34] A. M. FINK, A best possible Hadamard inequality, Math. Ineq. 83 Appl., 2 , pp. 223-230, (1998).

[35] A. M. FINK, Toward a theory of best possible inequalities, Nieuw Archief von Wiskunde, 12 , pp. 19-29, (1994).

[36] A. M. FINK, Two inequalities, Univ. Beograd Publ. Elektrotehn. Fak. Ser. Mat., 6, pp. 48-49, (1995).

[37] B. GAVREA, On Hadamard's inequality for the convex mappings defined on a convex domain in the space, Journal of Ineq. in Pure 6 Appl. Math., 1 (2000), No. 1, Article 9, http://jipam.vu.edu.au/

[38] P. M. GILL, C. E. M. PEARCE and J. PEČARIĆ, Hadamard's inequality for $r$-convex functions, J. of Math. Anal. and Appl., 215 , pp. 461-470, (1997).

[39] G. H. HARDY, J. E. LITTLEWOOD and G. PÓLYA, Inequalities, 2nd Ed., Cambridge University Press, (1952). 
[40] K.-C. LEE and K.-L. TSENG, On a weighted generalisation of Hadamard's inequality for $G$-convex functions, Tamsui Oxford Journal of Math. Sci., 16 (1), pp. 91-104, (2000).

[41] A. LUPAŞ, The Jensen-Hadamard inequality for convex functions of higher order, Octogon Math. Mag., 5, No. 2, pp. 8-9, (1997).

[42] A. LUPAŞ, A generalisation of Hadamard's inequality for convex functions, Univ. Beograd. Publ. Elek. Fak. Ser. Mat. Fiz., No. 544-576, pp. 115-121, (1976).

[43] D. M. MAKISIMOVIĆ, A short proof of generalized Hadamard's inequalities, Univ. Beograd. Publ. Elektrotehn. Fak. Ser. Mat. Fiz., No. 634-677, pp. 126-128, (1979).

[44] D.S. MITRINOVIĆ and I. LACKOVIĆ, Hermite and convexity, Aequat. Math., 28, pp. 229-232, (1985).

[45] D. S. MitrinOviĆ, J. E. PEČARIĆ and A. M. FINK, Classical and New Inequalities in Analysis, Kluwer Academic Publishers, Dordrecht/Boston/London.

[46] E. NEUMAN, Inequalities involving generalised symmetric means, $J$. Math. Anal. Appl., 120, pp. 315-320, (1986).

[47] E. NEUMAN and J. E. PEČARIĆ, Inequalities involving multivariate convex functions, J. Math. Anal. Appl., 137, pp. 514-549, (1989).

[48] E. NEUMAN, Inequalities involving multivariate convex functions II, Proc. Amer. Math. Soc., 109, pp. 965-974, (1990).

[49] C. P. NICULESCU, A note on the dual Hermite-Hadamard inequality, The Math. Gazette, July (2000).

[50] C. P. NICULESCU, Convexity according to the geometric mean, Math. Ineq. ${ }_{6}$ Appl., 3 (2), pp. 155-167, (2000).

[51] C. E. M. PEARCE, J. PEČARIĆ and V. ŠIMIĆ, Stolarsky means and Hadamard's inequality, J. Math. Anal. Appl., 220, pp. 99-109, (1998).

[52] C. E. M. PEARCE and A. M. RUBINOV, $P$-functions, quasi-convex functions and Hadamard-type inequalities, J. Math. Anal. Appl., 240, (1), pp. 92-104, (1999). 
[53] J. E. PEČARIĆ, Remarks on two interpolations of Hadamard's inequalities, Contributions, Macedonian Acad. of Sci. and Arts, Sect. of Math. and Technical Sciences, (Scopje), 13, pp. 9-12, (1992).

[54] J. PEČARIĆ and S. S. DRAGOMIR, A generalization of Hadamard's integral inequality for isotonic linear functionals, Rudovi Mat. (Sarajevo), 7 (1991), 103-107. MR 924: 26026. 2BL No. 738: 26006.

[55] J. PEČARIC, F. PROSCHAN and Y. L. TONG, Convex Functions, Partial Orderings and Statistical Applications, Academic Press, Inc., (1992).

[56] J. SÁNDOR, A note on the Jensen-Hadamard inequality, Anal. Numer. Theor. Approx., 19, No. 1, pp. 29-34, (1990).

[57] J. SÁNDOR, An application of the Jensen-Hadamard inequality, Nieuw-Arch.-Wisk., 8, No. 1, pp. 63-66, (1990).

[58] J. SÁNDOR, On the Jensen-Hadamard inequality, Studia Univ. BabesBolyai, Math., 36, No. 1, pp. 9-15, (1991).

[59] P. M. VASIĆ, I. B. LACKOVIĆ and D. M. MAKSIMOVIĆ, Note on convex functions IV: OnHadamard's inequality for weighted arithmetic means, Univ. Beograd Publ. Elek. Fak., Ser. Mat. Fiz., No. 678-715, pp. 199-205, (1980).

[60] G. S. YANG and M. C. HONG, A note on Hadamard's inequality, Tamkang J. Math., 28 (1), pp. 33-37, (1997).

[61] G. S. YANG and K. L. TSENG, On certain integral inequalities related to Hermite-Hadamard inequalities, J. Math. Anal. Appl., 239, pp. 180-187, (1999).

\section{S. S. Dragomir}

Mathematics

College of Engineering \& Science

Victoria University

P. O. Box 14428

Melbourne City

MC 8001

Australia

e-mail : sever.dragomir@vu.edu.au 
and

School of Computational \& Applied Mathematics

University of the Witwatersrand

Private Bag 3, Johannesburg 2050

South Africa

and

\section{Gomm}

Mathematics

College of Engineering \& Science

Victoria University

P. O. Box 14428

Melbourne City

MC 8001

Australia

e-mail : Ian.Gomm@vu.edu.au 